\title{
Household catastrophic payments for tuberculosis care in Nigeria: incidence, determinants, and policy implications for universal health coverage
}

Kingsley Nnanna Ukwaja ${ }^{*}$, Isaac Alobu², Seye Abimbola ${ }^{3}$ and Philip Christy Hopewell ${ }^{4}$

\begin{abstract}
Background: Studies on costs incurred by patients for tuberculosis (TB) care are limited as these costs are reported as averages, and the economic impact of the costs is estimated based on average patient/household incomes. Average expenditures do not represent the poor because they spend less on treatment compared to other economic groups. Thus, the extent to which TB expenditures risk sending households into, or further into, poverty and its determinants, is unknown. We assessed the incidence and determinants of household catastrophic payments for TB care in rural Nigeria.
\end{abstract}

Methods: Data used were obtained from a survey of 452 pulmonary TB patients sampled from three rural health facilities in Ebonyi State, Nigeria. Using household direct costs and income data, we analyzed the incidence of household catastrophic payments using, as thresholds, the traditional $>10 \%$ of household income and the $\geq 40 \%$ of non-food income, as recommended by the World Health Organization. We used logistic regression analysis to identify the determinants of catastrophic payments.

Results: Average direct household costs for TB were US\$157 or 14\% of average annual incomes. The incidence catastrophic payment was 44\%; with $69 \%$ and $15 \%$ of the poorest and richest household income-quartiles experiencing catastrophic activity, respectively. Independent determinants of catastrophic payments were: age $>40$ years (adjusted odds ratio [aOR] 3.9; 95\% confidence interval [Cl], 2.0, 7.8), male gender (aOR 3.0; $\mathrm{Cl} 1.8,5.2$ ), urban residence (aOR 3.8; Cl 1.9, 7.7), formal education (aOR 4.7; Cl 2.5, 8.9), care at a private facility (aOR 2.9; 1.5, 5.9), poor household (aOR 6.7; $\mathrm{Cl} 3.7,12)$, household where the patient is the primary earner (aOR 3.8; $\mathrm{Cl} 2.2,6.6]$ ), and HIV co-infection (aOR 3.1; Cl 1.7, 5.6).

Conclusions: Current cost-lowering strategies are not enough to prevent households from incurring catastrophic out-of-pocket payments for TB care. Financial and social protection interventions are needed for identified at-risk groups, and community-level interventions may reduce inefficiencies in the care-seeking pathway. These observations should inform post-2015 TB strategies and influence policy-making on health services that are meant to be free of charge.

Keywords: Cost analysis, Health policy, Tuberculosis, Regression analysis, Nigeria

\footnotetext{
* Correspondence: ukwajakingsley@yahoo.co.uk

'Department of Internal Medicine, Federal Teaching Hospital, Abakaliki,

Ebonyi State, Nigeria

Full list of author information is available at the end of the article
} 


\section{Multilingual abstracts}

Please see Additional file 1 for translations of the abstract into the six official working languages of the United Nations.

\section{Background}

Globally, over 150 million people are pushed into poverty annually because they have to pay for health services directly [1]. To reduce these financial risks, the World Health Organization (WHO) has asked countries to put in place innovative health financing systems to ensure universal health coverage (UHC) [1]. As well as that, an increasing numbers of global health players have acknowledged the need to achieve UHC [1]. The attainment of UHC was one of the main recommendations following the 2012 Global Symposium on Health Systems Research [2], and in December 2012, the United Nations passed a draft resolution that would support UHC for people everywhere [3].

There is a strong association between poverty and illhealth [4]. In particular, poor and vulnerable groups are at an increased risk of tuberculosis (TB) disease and mortality [5,6]. The costs patients incur due to illness, including $\mathrm{TB}$, remain central to the performance of health systems, particularly in terms of equity and coverage [1]. Excessive out-of-pocket (OOP) payments for health can discourage poor patients from seeking or continuing care [6,7]. In resource-poor countries, there is an urgent need to improve case-detection rates and treatment success of TB. Due to the strong link between poverty and $\mathrm{TB}$, this will likely require reducing the economic burden of care.

Several studies have assessed patient and household costs of TB care [6-8]. These studies have two major limitations. First, costs of TB care were reported as averages and the economic impact of these payments were estimated using average incomes [6-8]. Although poor patients generally spend less on treatment compared to other economic groups, the amount spent constitutes a higher proportion of their income [9]. Thus, reports based on any average income figure will likely underestimate the economic impact of illness for patients with a relatively low economic status, which includes an important proportion of TB patients. Second, the extent to which TB expenditures risk sending a household into, or further into, poverty and its determinants, is unknown.

Although, the WHO recommends that national TB programs lower patient costs of TB care-seeking through removal of user fees, decentralization of services, community-based care, and free diagnosis and treatment $[5,10]$, an important question that still needs to be answered empirically is whether household TB expenditures are large enough to require consumption of other goods to be sacrificed [11]. The basis of this concept is that such high level of spending must be at the expense of the consumption of other goods and services in the short- or long-term. This level of payments is often qualified as catastrophic [12-14]. Catastrophic healthcare expenditures have been defined by a rather arbitrary fraction of the total household income $(>10 \%)$ or of the total income net of subsistence expenditure $(\geq 40 \%)$ during a reference period [11-15]. The second definition better captures the ability to pay and better distinguishes between the rich and the poor $[15,16]$.

No studies have fully applied the same concept to assess the extent of catastrophic payments for TB care. Using data from a recent project on the economic impact of TB [17], and applying the same underlying conceptual framework as used for catastrophic health expenditures, this study investigated the incidence, intensity, distribution and correlates of catastrophic payments for TB care, and policy implications for TB care and other primary care services.

\section{Methods \\ Data}

The data used was obtained from a recent survey of 452 pulmonary TB patients sampled from three rural health facilities in Ebonyi State, Nigeria [17]. The survey's design is described below.

\section{Study setting}

Ebonyi State, located in the southeastern region of Nigeria has $73.6 \%$ of its 2.5 million population living below the poverty line [18]; and $75 \%$ of its inhabitants live in rural areas [19]. Because of the low availability of functional public sector health services, and the inability of the health system to recruit and retain health workers in rural settings of Ebonyi State, several not-for-profit mission (private) hospitals provide basic and secondary health services [17]. Since the Nigeria National TB Control Programme (NTP) was started, these not-for-profit mission hospitals and public (tertiary, secondary, and primary) health facilities have been involved in the decentralization of TB control services. Ebonyi State is divided into three geopolitical zones. The study was conducted in three rural hospitals (one public and two not-for-profit mission hospitals), one from each zone. Each of the study hospitals is a zonal referral center for TB services, and together, they accounted for $70 \%$ of TB case notification in Ebonyi State in 2009 [20].

Tuberculosis treatment at the hospitals surveyed was based on the community-based directly observed treatment short-course (community-DOTS) strategy in accordance with the guidelines of the NTP. Briefly, newlydiagnosed TB patients are treated with daily rifampicin, isoniazid, pyrazinamide, and ethambutol for two months of intensive treatment; followed by ethambutol and 
isoniazid for six months. During the first month of intensive phase of treatment for hospitalized patients, anti-TB medications are given and directly supervised at each study hospital by a medical staff of the hospital. Non-hospitalized TB patients attend weekly drug collection visits for their anti-TB medications. Therapy for patients treated on an outpatient basis was observed by a family member (DOTS-supporter) and/or a volunteer community health worker (CHW). At each drug collection visit, TB patients are required to come with their DOTS-supporter and the empty packs/sachets of used drugs. The activities of the DOTS-supporter and the CHW are monitored by the district $\mathrm{TB}$ control supervisors.

In Nigeria, households provide $70 \%$ of their total health expenditures and $90 \%$ of these occur through OOP payments [21]. Although a national policy that exempts TB patients/suspects from paying for consultations, laboratory tests, TB drugs, and hospitalization does exist, it was not effective at the not-for-profit mission hospitals surveyed. All patients who visited the mission hospital irrespective of their illness are required to pay a nominal consultation fee. Tuberculosis patients requiring hospital admissions were told to pay additional fees for accommodation and feeding, but TB laboratory tests and treatment are provided free of charge. At the public sector hospital surveyed, TB services (consultations, diagnostic tests, drugs, and hospitalization) are provided free of charge. However, feeding was not provided for TB patients who were hospitalized. There is no risk-pooling mechanism in financing health care as the National Health Insurance Scheme (NHIS) in Nigeria currently covers only federal government workers, who are $<5 \%$ of the population [22].

\section{Study design}

A cross-sectional study of new pulmonary TB patients was conducted between January and August 2011 to assess the costs of TB to patients and their households from the onset of the TB illness to diagnosis to the end of the intensive phase of treatment.

\section{Participants}

Only adult TB patients diagnosed based on sputum smear results with or without chest X-ray, and who had completed at least one month but less than three months of treatment i.e., between the 5th and 11th weekly drug collection visits, were included. Extrapulmonary TB patients, previously treated TB patients, and those with other co-morbidities except human immunodeficiency virus (HIV) were excluded. All the patients received community-DOTS.

\section{Sample size and sampling strategy}

Assuming that $50 \%$ of households with TB patients incur catastrophic OOP payments for TB care at 95\% confidence level and an absolute sampling error of 5\%, a minimum of 378 patients were needed. The sample size was increased to 480 to account for potential refusals and to allow additional variables in the logistic regression analysis. Consecutive eligible patients were interviewed at each study facility until the required sample size was reached.

\section{Data collection}

A standardized questionnaire (tool to estimate patient cost) from the WHO/Stop-TB partnership was used for the survey [23]. The questions included a detailed list of the expenses that might be incurred by $\mathrm{TB}$ patients in their pathway to care i.e., from illness onset to visit to any health provider(s) to diagnosis to treatment. Also, there were other questions which also quantified the incomes and food expenditures of the patients and their households before the onset TB symptoms, and at the point when $\mathrm{TB}$ was diagnosed and treatment was started [23]. The annual income of each patient's household was estimated from their mean monthly income reported at the time of their diagnosis.

Data was collected by two CHWs with Bachelor's degrees. All the patients were interviewed in their preferred language during their drug collection visit to the study hospitals and each interview lasted an average of 30 minutes. Quality control was carried out by the respective district TB control officers charged with guiding and inspecting every step of the survey, and was also carried out weekly by the principal investigator.

\section{Measuring catastrophic payments}

Using household direct cost for TB care and income data, we analyzed the incidence of household catastrophic payments and its determinants. Patient direct costs include the medical OOP payments (e.g. consultation fees, laboratory tests, drugs from any source, and hospital care) and the non-medical OOP expenses (e.g. the costs of travel, services provided by traditional healers, any food supplements, and coping costs). For each household, the total household direct payment for TB care was the sum of the direct patient costs and the direct DOTS-supporter costs (see Table 1).

The incidence of catastrophic payments is estimated from the fraction of a population sample with healthcare costs as a share of the total income or non-food expenditure exceeding the chosen threshold. Most previous studies reported that an OOP payment greater than $10 \%$ of the total household income is catastrophic [12], while the WHO and World Bank defined total OOP payments equaling or exceeding $40 \%$ of the non-food household 
Table 1 Cost definitions used in the study

\begin{tabular}{ll}
\hline Variable & Definition \\
\hline Direct cost & $\begin{array}{l}\text { Out-of-pocket payment for TB services and those incurred in the pathway to care to access the service. These include user } \\
\text { fees, consultation fees, laboratory test fees, travel costs, food costs, and other costs. }\end{array}$ \\
$\begin{array}{l}\text { Household cost } \\
\text { for each patient, this is the sum of patient direct pre-diagnosis cost, direct coping cost, direct post-diagnosis cost, and } \\
\text { direct DOTS-supporter cost. } \\
\text { Costs incurred by patients who attempted to cope with the costs of TB care by borrowing money or selling their assets. It } \\
\text { is estimated as a sum of interest paid for loans and/or the difference in the market value of assets sold. }\end{array}$ \\
$\begin{array}{l}\text { Dots-supporter cost } \\
\begin{array}{l}\text { The-diagnosis/ } \\
\text { diagnosis cost }\end{array}\end{array}$ \\
$\begin{array}{l}\text { The direct costs incurred by family members looking after/accompanying the patient during care. } \\
\text { Post-diagnosis cost }\end{array}$ & $\begin{array}{l}\text { The direct costs incurred in the period from the start to the completion of the intensive phase of treatment } \\
\text { (approximately two months). }\end{array}$ \\
\hline
\end{tabular}

$\mathrm{TB}=$ tuberculosis; DOTS = directly observed treatment short-course strategy.

income (capacity to pay) as catastrophic [13-15]. The WHO approach is the widely accepted method for measuring the incidence of catastrophic payments [13-16]. In this study, catastrophic payments for TB care was estimated using the two measurement methods, and sensitivities of varying thresholds were determined. These two concepts are illustrated in the conceptual framework detailed in (see Table 2).

Households that earned less than the median annual income reported during the study (\$1040) were classified as poor households and those that earned more than the median were classified as less-poor. All costs were captured in Nigeria Naira (N) and converted to the 2011 US $\$$ rate $(1 \mathrm{US} \$=\mathrm{N} 150)$.

\section{Data analysis}

The data were double entered, checked, and analyzed using Epi Info 3.4.1 (CDC, Atlanta, GA USA). The normality of direct cost data distribution was assessed using visual inspection of graphs created using the data and Chebyshev's rule of frequency distribution. Direct costs were normally distributed. Continuous variables were summarized as means ( \pm standard deviation [SD]) while categorical variables were summarized as proportions (\%). Categorical group comparisons were made using the Chi-squared test. Odds ratios and their 95\% confidence intervals (CIs) were estimated using multivariable logistic regression analysis, with household catastrophic payments (i.e., $\geq 40 \%$ of capacity to pay) as an outcome variable. The likelihood ratio test was used to assess the association between explanatory variables and household catastrophic payments. We performed a stratified analysis to determine the occurrence of interaction and confounding between the outcome variable and explanatory variables. Multivariable models were then constructed, including all variables of clinical importance and all with bivariate $\mathrm{P}<0.25$. A backward elimination approach was used to find the best model. All P-values were bidirectional and significance was set at a P-value of less than 0.05 .

\section{Ethical issues}

Written informed consent was sought from all study participants. The research protocol was approved by the Ebonyi State University Teaching Hospital Health Research and Ethics Committee.

\section{Results}

Household income and OOP payments for TB

Complete data from 452 patients and their households were available for our analysis. The average household annual income was US $\$ 1123$ of which an average of $47 \%$ was spent on food. Mean direct household payments for TB were US\$157 or $14 \%$ of the average annual income. About $45 \%$ of this amount was spent before TB was diagnosed and $25 \%$ each during treatment and through

Table 2 Conceptual framework

\begin{tabular}{|c|c|c|c|c|}
\hline $\begin{array}{l}\text { Out-of-pocket } \\
\text { (direct) costs for } \\
\text { tuberculosis care }\end{array}$ & $\begin{array}{l}\text { Economic } \\
\text { burden }\end{array}$ & Measurement tools & Indicators & Interpretation and implications \\
\hline & $\begin{array}{l}\text { Catastrophic } \\
\text { payments (I) }\end{array}$ & $\begin{array}{l}\text { Percentage of direct costs } \\
\text { exceeding } 10 \% \text { of the } \\
\text { household income }\end{array}$ & $\begin{array}{l}\text { Incidence }(\%) \text { and intensity using } \\
\text { various income thresholds }[5 \% \text {, } \\
10 \%, 15 \%, 20 \%, 25 \%]\end{array}$ & $\begin{array}{l}\text { Which rates of catastrophic costs using income } \\
\text { threshold agrees with the burden estimated } \\
\text { using } \geq 40 \% \text { of non-food expenditure (II) }\end{array}$ \\
\hline & $\begin{array}{l}\text { Catastrophic } \\
\text { payments (II) }\end{array}$ & $\begin{array}{l}\text { Percentage of direct costs } \\
\text { greater than or equal to } \\
40 \% \text { of the non-food } \\
\text { income }\end{array}$ & $\begin{array}{l}\text { Incidence }(\%) \text { and intensity using } \\
\text { various thresholds of non-food } \\
\text { expenditure }[\geq 15 \%, \geq 25 \%, \geq 40 \%]\end{array}$ & $\begin{array}{l}\text { Distribution of catastrophic costs of care across } \\
\text { patient characteristics and its determinants }\end{array}$ \\
\hline
\end{tabular}


coping strategies adopted by the household (see Table 3). Drugs from several sources (35\%), laboratory tests (30\%), and transportation (21\%) during the care-seeking pathway accounted for most payments from the onset of illness up until diagnosis. Transportation (70\%), hospitalization (15\%), and feeding (13\%) accounted for the majority of costs during treatment.

\section{Catastrophic payment in different income groups}

The rate of catastrophic payments for TB was inversely associated with the household income level. Ninety-five percent of households spent at least $5 \%$ of their income on TB treatment (direct cost), $65 \%$ spent at least $10 \%$, and $37 \%$ spent at least $15 \%$. Defining catastrophic payments using the current WHO definition, $44 \%$ of households incurred catastrophic payments for TB care. The average OOP payments and capacity to pay rose steadily with rising income quartile i.e., the wealthier the quartiles, the higher the OOP payments and capacity to pay. However, the economic burden faced by households in the richer income quartiles was proportionally lower due to their higher capacity to pay (see Table 4). Thus, although the average direct costs of TB care increased from US\$128 among the households in the lowest income quartile to US\$208 among those in the highest income quartile (Chi-square for trend 39, $P<0.001$ ), the proportion of households who incurred catastrophic payments decreased from $69 \%$ among households belonging to the poorest income quartile to $15 \%$ among those belonging to the richest income quartile (Chisquare for trend $148, P<0.001)$.

\section{Threshold level for catastrophic payment}

The sensitivity of the analysis to different threshold levels of catastrophic payments was tested as shown (see Table 5). The head count is the percentage of households whose direct costs, expressed as a proportion of income, exceeds a given discretionary fraction of their income, z. The mean gap is the average amount by which payments, as a proportion of income, exceed the threshold z. The head count (a measure of incidence) and mean gap are related through the mean positive gap (a measure of intensity), which is defined as the head count being a fraction of the mean gap. The table shows that as much as $44 \%$ of the sample recorded OOP payments for TB as a proportion of income which exceeded $40 \%$ of their capacity to pay. The related mean gap was $8.3 \%$, which means that on average, TB-related expenditures were $8.3 \%$ higher than the $40 \%$ threshold.

\section{Catastrophic payment distribution}

We compared catastrophic TB-related expenditure rates among various patients and households with different characteristics (see Table 6). Households with a male patient had a greater risk of experiencing catastrophic payments than those with a female patient. Urban households had a higher risk of experiencing catastrophic payments than rural households. Poor households had a greater risk of incurring catastrophic payments than less-poor households. Patients who received care at a private facility had a higher risk of catastrophic payments than those who were treated at a public facility. Also, households with a patient who was the household primary income earner had a higher risk of incurring catastrophic payments than those who were not.

\section{Determinants of catastrophic payment}

Logistic regression analysis yielded a wide range of independent determinants of catastrophic TB-related expenditure (see Table 7). Households with a male patient, a patient $>40$ years, a patient with formal education (i.e., completed at least six years of schooling), or who was the primary income earner for their household were more likely to experience catastrophic payments. Urban residence, care at a private facility, and HIV co-infection were other independent determinants of catastrophic payments for TB care.

\section{Discussion}

The incidence and intensity of catastrophic payments for TB care could provide an insight into the level of financial protection a healthcare financing system affords its population [24]. It shows the financial burden faced by

Table 3 Household direct payments for TB care in Nigeria, 2011

\begin{tabular}{lll}
\hline Source of direct cost & Mean costs $( \pm$ SD) in US\$ & Percentage of mean annual household income $(\%)$ \\
\hline Patient pre-diagnosis & $70( \pm 48.4)$ & 6.2 \\
Patient post-diagnosis & $40( \pm 32.2)$ & 3.6 \\
DOTS-supporter & $7( \pm 6.5)$ & 0.6 \\
Coping cost & $40( \pm 38.5)$ & 3.6 \\
Total & 157 & 14
\end{tabular}

US\$ = United States dollar.

Mean annual household income at TB diagnosis = US\$1123.

$\mathrm{SD}=$ Standard deviation .

Note: Based on a currency exchange rate of 150 Nigeria Naira to US\$1.00. 
Table 4 Distribution of household direct costs and incidence of catastrophic payments for TB across income quartiles, Nigeria, 2011

\begin{tabular}{|c|c|c|c|c|c|}
\hline \multirow[t]{2}{*}{ Indicator } & \multicolumn{5}{|c|}{ Income quartile $^{a}$} \\
\hline & Q1 & Q2 & Q3 & Q4 & All \\
\hline Frequency & 174 & 66 & 134 & 78 & 452 \\
\hline Average direct costs of TB care (US\$) ${ }^{b}$ & 128 & 144 & 158 & 208 & 157 \\
\hline Average annual household income (US\$) & 644 & 880 & 1313 & 2071 & 1123 \\
\hline Direct costs share of household income (\%) & 20 & 16 & 12 & 10 & 14 \\
\hline Average capacity to pay (US\$) & 319 & 320 & 675 & 985 & 540 \\
\hline \multicolumn{6}{|l|}{ Households with catastrophic expenditure (\%) } \\
\hline$I=>10 \%$ of household income & 88 & 100 & 45 & 31 & 65 \\
\hline$\|=\geq 40 \%$ of capacity to pay & 69 & 46 & 27 & 15 & 44 \\
\hline
\end{tabular}

US\$ = United States dollar.

${ }^{a}$ Quartile 1 is the poorest and Quartile 4 is the wealthiest.

based on a currency exchange rate of 150 Nigeria Naira to US\$1.00.

'Capacity to pay = household income minus food expenditure (income after expenditures for food).

households of TB patients, and the economic and information barriers that impair prompt and appropriate TBcare seeking. Thus, although TB care is supposedly free of charge, patients/households have to make significant OOP payments in their pathway to diagnosis and treatment. In this study, incidence of catastrophic payment was $44 \%$. The rates observed are higher than those estimated for catastrophic health expenditure, in general, in African and other low-income countries [24,25].

About half of the costs incurred by the patients were made before diagnosis. This suggests that $\mathrm{TB}$ patients incur substantial OOP payments before reaching a health facility where the disease can be diagnosed. This high pre-diagnosis cost may be due to poor community knowledge of TB resulting in long delays and inappropriate care seeking at informal providers for TB symptoms [26]. Furthermore, it may be that the informal/ non-NTP providers kept the patients for profits, or had low capacity to diagnose and refer $\mathrm{TB}$ suspects to a DOTS facility. Reducing the high pre-diagnosis costs may require improving community knowledge of $\mathrm{TB}$,

Table 5 Incidence and intensity of catastrophic payments for TB care, Nigeria 2011

\begin{tabular}{lccccc}
\hline Catastrophic payment & \multicolumn{6}{c}{ Threshold level (z) } \\
\hline & $\mathbf{5 \%}$ & $\mathbf{1 0 \%}$ & $\mathbf{1 5 \%}$ & $\mathbf{2 5 \%}$ & $\mathbf{4 0 \%}$ \\
Out-of-pocket TB spending: as a share of total expenditure & \\
$\quad$ Head count (\%) & 95 & 65 & 37 & 9 & \\
$\quad$ Mean gap (\%) & 7.5 & 6.0 & 4.6 & 2.1 & \\
$\quad$ Mean positive gap (\%) & 7.9 & 9.3 & 12.5 & 22.9 & \\
as a share of non-food expenditure & & & & & \\
$\quad$ Head count (\%) & & & 84 & 68 & 44 \\
$\quad$ Mean gap (\%) & & & 12.3 & 10.7 & 8.3 \\
Mean positive gap (\%) & & & 14.8 & 15.9 & 19.1 \\
\hline
\end{tabular}

further decentralization of TB services to rural communities, and involving informal/non-NTP providers in TB service delivery.

\section{Socioeconomic status and catastrophic payment}

Our findings showed that economic status was a key determinant of catastrophic payments. This result is similar to what was previously documented $[24,25]$. Payments for TB care reduced more of the average capacity to pay/income of the two poorest income groups (Q1 and Q2). As previously reported [13], three conditions are required for catastrophic payments to occur: the availability of health services requiring payment, low capacity to pay, and the absence of prepayment mechanisms. Health services for TB are available in the setting, but there is high usage of the private/informal sector requiring payments [26]. The use of informal providers have been shown in other studies in southeast Nigeria and elsewhere to be common among the poor, and may contribute to their high rates of catastrophic health payments $[27,28]$. Although TB care at the public sector is free, inequities in the distribution of effective public sector services between the rural and urban areas as well as "under-the-table payments" may account for high rates of catastrophic payments among those who received care in the rural public sector. With about $70 \%$ of Nigerians living on less than US\$1 per day [18], high poverty rates may account for the low capacity to pay among households with a TB patient. In addition, their more costly and tortuous care-seeking pathway [26,29], results in substantial OOP payments as most households are not covered by prepayment mechanisms [22].

\section{Factors associated with catastrophic payments}

Logistic regression analysis showed that demographic factors such as age, gender, education, being the primary 
Table 6 Relationship between patients' characteristics, average household direct costs, and rate of catastrophic payments for TB, Nigeria, 2011

\begin{tabular}{|c|c|c|c|c|c|c|}
\hline Variable & Direct costs (US\$) & T-test & $P$ & Rate of catastrophic payment n (\%) & $\mathrm{x}^{2}$ & $P$ \\
\hline Age (years) & & 6.01 & $<0.001$ & & 0.024 & 0.9 \\
\hline$\leq 40$ & 144 & & & $150(43.6)$ & & \\
\hline$>40$ & 197 & & & $48(44.4)$ & & \\
\hline Gender & & 4.2 & $<0.001$ & & 26.1 & $<0.001$ \\
\hline Male & 171 & & & $138(54.3)$ & & \\
\hline Female & 138 & & & $60(30.3)$ & & \\
\hline Residence & & 3.1 & 0.002 & & 69 & $<0.0$ \\
\hline Urban & 180 & & & $78(81.3)$ & & \\
\hline Rural & 150 & & & $120(33.7)$ & & \\
\hline Education & & 0.88 & 0.4 & & 40.3 & $<0.001$ \\
\hline No formal education & 153 & & & $42(24.7)$ & & \\
\hline Formal education & 159 & & & $156(55.3)$ & & \\
\hline Primary income earner & & 4.1 & $<0.001$ & & 56.3 & $<0.001$ \\
\hline Yes & 174 & & & $126(63.6)$ & & \\
\hline No & 143 & & & $72(28.3)$ & & \\
\hline Household income level & & 2.6 & 0.01 & & 72.8 & $<0.001$ \\
\hline Poor & 144 & & & $120(69)$ & & \\
\hline Less-poor & 165 & & & $78(28.1)$ & & \\
\hline Category of facility & & 0.7 & 0.47 & & 37.6 & $<0.001$ \\
\hline Public & 161 & & & $24(20)$ & & \\
\hline Private & 155 & & & $174(52.4)$ & & \\
\hline Smear status & & 0.02 & 0.98 & & 0.66 & 0.42 \\
\hline Smear positive & 157 & & & $162(44.8)$ & & \\
\hline Smear negative & 157 & & & $36(40)$ & & \\
\hline HIV status & & 4.4 & $<0.001$ & & 1.3 & 0.25 \\
\hline Positive & 168 & & & $66(45)$ & & \\
\hline Negative & 131 & & & $132(42)$ & & \\
\hline
\end{tabular}

HIV = human immunodeficiency virus.

household earner, and residence independently influenced the risk of catastrophic payment for TB care.

Table 7 Determinants of catastrophic payments ${ }^{a}$ for TB care, Nigeria, 2011

\begin{tabular}{lllll}
\hline Variable & Coeff & Standard error & P-value & Odds ratio (95\% Cl) \\
\hline Older age (>40 years) & 1.368 & 0.35 & $<0.001$ & $3.9(2.0-7.8)$ \\
Male gender & 1.11 & 0.28 & $<0.001$ & $3.0(1.8-5.2)$ \\
Urban residence & 1.34 & 0.36 & $<0.001$ & $3.8(1.9-7.7)$ \\
Formal education & 1.55 & 0.33 & $<0.001$ & $4.7(2.5-8.9)$ \\
Care at private facility & 1.10 & 0.36 & 0.003 & $2.9(1.5-5.9)$ \\
Poor patients & 1.91 & 0.31 & $<0.001$ & $6.7(3.7-12.4)$ \\
Household primary earner (patient) & 1.33 & 0.28 & $<0.001$ & $3.8(2.2-6.6)$ \\
HIV (positive) status & 1.13 & 0.30 & $<0.001$ & $3.1(1.7-5.6)$ \\
Smear positive TB & 0.10 & 0.35 & 0.77 & $1.1(0.6-2.2)$ \\
Constant & 2.11 & 0.52 & $<0.001$ & \\
\hline
\end{tabular}

Coeff. $=$ coefficient expressed in logits; $\mathrm{Cl}=95 \%$ confidence interval for the odds ratio, $\mathrm{TB}=$ tuberculosis, $\mathrm{HIV}=$ human immunodeficiency virus . 
Households with a male patient, a patient over 40 years, a patient with formal education, or a patient who is the primary earner were more likely to incur catastrophic payments. Patients from urban households incurred higher rates of catastrophic payments because the study health facilities were located in the rural area thus transportation costs to the rural hospitals may be the main culprit. Households with male patients are more affected because in the setting, men are the primary income earners. The high rate of catastrophic payments in households with older patients may occur because with increasing age, patients are more likely to visit a hospital with a DOT-supporter accounting for higher costs.

HIV co-infection was also found to be an important determinant of catastrophic payments. A previous study suggests that $\mathrm{TB} / \mathrm{HIV}$ co-infection could be less costly to patients because of TB/HIV collaborative activities [30]. However, we found that households with a HIV-infected patient were three times more likely to incur catastrophic payments than those without. Thus, households with a HIV-infected patient in similar settings should be targets for financial protection mechanisms.

\section{Limitations of the analysis}

This study had some limitations. First, it captures the incidence of catastrophic OOP payments of households with TB patients who sought care and did not consider those who need services but could not afford them. This could lead to underestimation of the incidence and intensity of catastrophic payments. Second, households may suffer additional financial problems because of foregone income associated with TB disease [6]. We deliberately focused only on estimating the financial catastrophe associated with OOP payments made for TB care because high OOP payments may discourage early care seeking or push the patient/household into poverty [1]. Other potential limitations include the use of crosssectional survey data and recall bias. Data were collected when the patients had recently started treatment and should have a better recall of their care-seeking pathway. Further qualitative research will complement and enrich the findings of this study.

\section{Conclusions}

In conclusion, $44 \%$ of households incurred catastrophic payments for TB care, and the proportion of households who incurred catastrophic payments for TB care was inversely associated with their household income. Our study points to four important implications for health policymakers. First, Nigeria and other high-burden TB countries must move away from OOP payments for health care. There is a need to institute financial protection against catastrophic payments through prepayment mechanisms. This may be achieved through a mix of tax-based, social health, and community-based insurance schemes. Second, policymakers can use the findings in this paper to better target beneficiaries of financial riskprotection strategies. Importantly, there is a need to develop strategies to better protect households with TB patients who are older than 40 years, male, educated, primary household earners, and HIV infected against catastrophic payments associated with paying for TB care. Third, there is a need to reduce the cost of TB care by curbing unnecessary pre-diagnosis costs (e.g., from inappropriate care-seeking and irrational drug use), and strengthening lower-level providers. This can be achieved through extensive community engagement mechanisms to restructure the institutional arrangements around the health service uptake through education, and empowerment of informal providers and their use as referral points in the service chain.

Finally, the current low TB detection rate in highburden countries implies that current approaches to reduce patient costs of care are not enough to prevent TBaffected households from incurring catastrophic payments. It also suggests that very poor patients may not be able to afford care. Decision makers may need to institute social protection interventions such as food or cash transfers, and microcredit schemes for TB patients in high-burden countries. Our observations should not only inform the ongoing consultations on sustainable post-2015 strategies for TB care and control, but also influence the thinking of national and global health policymakers on how to plan for free health services to ensure that these services are actually free of charge.

\section{Additional file}

Additional file 1 Multilingual abstracts in the six official working languages of the United Nations.

\section{Competing interests}

The authors declare that they have no competing interests.

\section{Authors' contributions}

KNU led the study from conception, design and data collection to the drafting of the article. IA contributed to the design, interpretation of data, and drafting of the article. SA contributed to data analysis, and interpretation and drafting of the article. PCH contributed to the conception, design, and revising the manuscript critically for important intellectual content. All authors gave final approval.

\section{Authors' information}

$\mathrm{KNU}$ is an Internal Medicine resident clinician and a facilitator for the National TB and Leprosy Control Programme in Ebonyi State. IA is a public health physician and the program officer of the National TB and Leprosy Control Programme in Ebonyi State. SA is an epidemiologist and a project fellow of the National Primary Health Care Development Agency, Abuja, Nigeria. PCH is a Professor in residence, Division of Pulmonary and Critical Care Medicine, San Francisco General Hospital, and the Principal Investigator of the Francis J Curry International Tuberculosis Center, 


\section{Acknowledgements}

KNU acknowledges the entire faculty of the Pan African Thoracic Society's Methods in Epidemiologic, Clinical and Operations Research (PATS-MECOR) course who helped during the design of the study and writing of the manuscript. This work was supported by a 2010 PATS-MECOR small grant award received by KNU. The funding source had no role in the study design, data analysis/interpretation, manuscript writing, or the decision to submit the manuscript for publication.

\section{Author details}

'Department of Internal Medicine, Federal Teaching Hospital, Abakaliki, Ebonyi State, Nigeria. ${ }^{2}$ National Tuberculosis and Leprosy Control Programme, Ministry of Health, Abakaliki, Ebonyi State, Nigeria. ${ }^{3}$ National Primary Health Care Development Agency, Abuja, Nigeria. ${ }^{4}$ Francis J Curry International Tuberculosis Center, Division of Pulmonary and Critical Care Medicine, San Francisco General Hospital, University of California, San Francisco, CA, USA.

Received: 17 May 2013 Accepted: 12 September 2013

Published: 17 September 2013

\section{References}

1. The World Health Report: Health Systems Financing: the Path to Universal Coverage. Geneva: World Health Organization; 2010.

2. Inclusion and Innovation Towards Universal Coverage - the 2012 Global Symposium on Health Systems Research. http://www.healthsystemsglobal. org/GlobalSymposia.aspx (accessed 10/01/2013).

3. Global Health and Foreign Policy. United Nations; 2012. [http://www.un.org/ ga/search/view_doc.asp?symbol=A/67/L.36] (accessed 10/01/2013).

4. Braveman P, Gruskin S: Poverty, equity, human rights and health. Bull World Health Organ 2003, 81:539-545.

5. World Health Organization: Addressing Poverty in TB Control - World Health Organization Report-2005. Geneva: World Health Organization; 2005.

6. Ukwaja KN, Modebe O, Igwenyi C, Alobu I: The economic burden of tuberculosis care for patients and households in Africa: a systematic review. Int J Tuberc Lung Dis 2012, 16:733-739.

7. Long Q, Smith H, Zhang T, Tang S, Garner P: Patient medical costs for tuberculosis treatment and impact on adherence in China: a systematic review. BMC Public Health 2011, 11:393.

8. Laokri S, Weil O, Maxime Drabo K, Dembele SM, Kafando B, Dujardin B: Removal of user fees no guarantee of universal health coverage: observations from Burkina Faso. Bull World Health Organ 2013, 91:277-282.

9. Zaman S, Rahman H, Edgewirth R: Health Domain of the Ultra Poor: an Exploration. Dhaka and Ottawa: BRAC Centre Bangladesh and Aga Khan Foundation Canada; 2004.

10. World Health Organization: Integrating Community-Based Tuberculosis Activities into the Work of non-Governmental and Other Civil Society Organizations: Operational Guidance. Geneva: World Health Organization; 2012.

11. Kawabata K, Xu K, Carrin G: Preventing impoverishment through protection against catastrophic health expenditure. Bull World Health Organ 2002, 80:612.

12. Wagstaff $A$, van Doorslaer $E$ : Catastrophe and impoverishment in paying for health care: with applications to Vietnam 1993-1998. Health Econ 2003, 12:921-932.

13. Xu K, Evans D, Kwabata K, Zeramdini R, Klavus J, Murray CJ: Household catastrophic health expenditure: a multi-country analysis. Lancet 2003, 363:111-117.

14. Xu K: Distribution of Health Payments and Catastrophic Expenditures: Methodology. Geneva: World Health Organization; 2005.

15. O'Donnell O, Van Doorslaer E, Wagstaff A, Lindelow M: Analyzing Health Equity Using Household Survey Data. A Guide to Techniques and Their Implementation. Washington D.C: World Bank; 2008.

16. Bonu S, Bhushan I, Rani M, Anderson I: Incidence and correlates of 'catastrophic' maternal health care expenditure in India. Health Policy Plan 2009, 24:445-456.

17. Ukwaja KN, Alobu I, Igwenyi C, Hopewell PC: The high costs of free tuberculosis services: patient and household costs associated with tuberculosis care in Ebonyi state, Nigeria. PLoS One 2013, 8:e73134.
18. The Nigeria poverty profile: 2010 report, Nigerian National Bureau of Statistics 2012. http://resourcedat.com/resources/The-Nigerian-Poverty-Profile1.pdf (accessed 10/01/2013).

19. Commission TNP: 2006 Population and Housing Census of the Federal Republic of Nigeria. Priority Tables (Volume I). The National Population Commission: Abuja; 2009.

20. Ukwaja K, Alobu I, Ifebunandu N, Osakwe C, Igwenyi C: From DOTS to the stop TB strategy: DOTS coverage and trend of tuberculosis notification in ebonyi, southeastern Nigeria, 1998-2009. Pan Afr Med J 2011, 9:12.

21. Soyibo A, Lawanson O, Olaniyan L: National Health Accounts of Nigeria, 1998-2002 - Final Report Submitted to WHO. Ibadan and Geneva: University of Ibadan \& World Health Organization; 2005.

22. Scheme NHI: Road map for the Implementation of Community-Based Health Insurance Scheme in Nigeria: Consultations on Support to Community-Based Health Insurance Scheme Roll-out in Programme States. Abuja: PPRINN-MNCH /NHIS; 2011.

23. World Health Organization Stop TB Partnership: Tools to Estimate Patient Costs. Geneva: World Health Organization; 2007.

24. Li Y, Wu Q, Legge D, Hao Y, Gao L, Ning N, Wan G: Factors affecting catastrophic health expenditure and impoverishment from medical expenses in china: policy implications of universal health insurance. Bull World Health Organ 2012, 90:664-671.

25. Su TT, Kouyate B, Flessa S: Catastrophic household expenditure for health in a low-income society: a study from mouna district, Burkina Faso. Bull World Health Organ 2006, 84:21-27.

26. Ukwaja KN, Alobu I, Nweke CO, Onyenwe CE: Healthcare-seeking behavior, treatment delays and its determinants among pulmonary tuberculosis patients in rural Nigeria: a cross-sectional study. BMC Health Serv Res 2013, 13:25.

27. Onwujekwe O, Onoka O, Uzochukwu B, Hanson K: Constraints to universal coverage: inequities in health service use and expenditures for different health conditions and providers. Int J Equity Health 2011, 10:50.

28. Makinen M, Waters H, Rauch M, Almagambetova N, Bitran R, Gilson L, McIntyre D, Pannarunothai S, Prieto AL, Ubilla G, Ram S: Inequalities in health care use and expenditures: empirical data from eight developing countries in transition. Bull World Health Organ 2000, 78:55-65.

29. Kapoor SK, Raman AV, Sachdeva KS, Satyanarayana S: How did the TB patients reach DOTS services in Delhi? A study of patient treatment seeking behavior. PLoS One 2012, 7:e42458.

30. Vassall A, Seme A, Compernolle P, Meheus F: Patient costs of accessing collaborative tuberculosis and human immunodeficiency virus interventions in Ethiopia. Int J Tuberc Lung Dis 2010, 14:604-610.

doi:10.1186/2049-9957-2-21

Cite this article as: Ukwaja et al:: Household catastrophic payments for tuberculosis care in Nigeria: incidence, determinants, and policy implications for universal health coverage. Infectious Diseases of poverty 2013 2:21.

\section{Submit your next manuscript to BioMed Central and take full advantage of:}

- Convenient online submission

- Thorough peer review

- No space constraints or color figure charges

- Immediate publication on acceptance

- Inclusion in PubMed, CAS, Scopus and Google Scholar

- Research which is freely available for redistribution 